\title{
Prediction model of moisture content of dead fine fuel in forest plantations on Maoer Mountain, Northeast China
}

\author{
Maombi Mbusa Masinda ${ }^{1,2} \cdot \mathrm{Fei} \mathrm{Li}^{1} \cdot \mathrm{Qi} \mathrm{Liu}^{1} \cdot$ \\ Long Sun ${ }^{1}$ Tongxin $\mathrm{Hu}^{1}$
}

Received: 5 March 2020 / Accepted: 19 May 2020 / Published online: 4 January 2021

(C) The Author(s) 2021

\begin{abstract}
Preventing and suppressing forest fires is one of the main tasks of forestry agencies to reduce resource loss and requires a thorough understanding of the importance of factors affecting their occurrence. This study was carried out in forest plantations on Maoer Mountain in order to develop models for predicting the moisture content of dead fine fuel using meteorological and soil variables. Models by Nelson (Can J For Res 14:597-600, 1984) and Van Wagner and Pickett (Can For Service 33, 1985) describing the equilibrium moisture content as a function of relative humidity and temperature were evaluated. A random forest and generalized additive models were built to select the most
\end{abstract}

Long Sun, Tongxin Hu contributed equally to this work

Project funding: This work was supported by the National Key Research and Development Program of China, Key Projects for Strategic International Innovative Cooperation in Science and Technology (2018YFE0207800), Fundamental Research Funds for the Central Universities (2572019BA03), and partly by the China Scholarship Council (CSC No.2016DFH417).

The online version is available at http://www.springerlink.com

Corresponding editor: Yanbo $\mathrm{Hu}$

Supplementary information The online version contains supplementary material available at (https://doi.org/10.1007/ s11676-020-01280-x).

Long Sun

sunlong365@126.com

Tongxin $\mathrm{Hu}$

htxhtxapple@sina.com

1 Key Laboratory of Sustainable Forest Ecosystem Management-Ministry of Education, College of Forestry, Northeast Forestry University, 26 Hexing Road, Harbin 150040, People's Republic of China important meteorological variables affecting fuel moisture content. Nelson's (Can J For Res 14:597-600, 1984) model was accurate for Pinus koraiensis, Pinus sylvestris, Larix gmelinii and mixed Larix gmelinii-Ulmus propinqua fuels. The random forest model showed that temperature and relative humidity were the most important factors affecting fuel moisture content. The generalized additive regression model showed that temperature, relative humidity and rain were the main drivers affecting fuel moisture content. In addition to the combined effects of temperature, rainfall and relative humidity, solar radiation or wind speed were also significant on some sites. In P. koraiensis and P. sylvestris plantations, where soil parameters were measured, rain, soil moisture and temperature were the main factors of fuel moisture content. The accuracies of the random forest model and generalized additive model were similar, however, the random forest model was more accurate but underestimated the effect of rain on fuel moisture.

Keywords Forest plantations - Fine fuel moisture content $\cdot$ Weather factors $\cdot$ Prediction models

2 Faculty of Sciences, Université Officielle de Ruwenzori, PO Box 560, Butembo, North Kivu, Democratic Republic of Congo 


\section{Introduction}

Forest plantations provide timber and wood products, thereby contributing to the economic development of many countries (Carnus et al. 2006). Recent statistics of forest cover show that China has $24 \%$ of the world's forest plantations (Shen et al. 2019). In temperate and boreal regions, forests are threatened by fires whose frequency and intensity tend to increase due to human activities and climate change (Beach et al. 2010). However, fire is also one of the main factors contributing to forest renewal and succession, and plays an essential role in maintaining biodiversity and landscape heterogeneity (Chang et al. 2013). Despite their natural functions, fires of high intensity constitute a danger to forest ecosystems, human life, and infrastructure, and are a source of greenhouse gas emissions. Therefore, preventing and suppressing forest fires is one of the main tasks of forest agencies to reduce losses. This requires a good understanding of factors affecting fire occurrence.

According to the Global Fire Monitoring Centre (https:// gfmc.online/inventory/statistic.html) of Germany's Freiburg University, fires occur on several hundred million hectares of forest and other vegetation around the world each year. In China, forest fires are reported in different provinces of the country, however up to now, forest fire statistics are not reported to the Global Fire Monitoring Centre. In Heilongjiang Province in northeast of China, the mean annual area of burned forest varies between 500 and $2500 \mathrm{~km}^{2}$ ( $\mathrm{Li}$ et al. 2015). This average represents $0.25-1.2 \%$ of the forest cover of Heilongjiang Province, estimated at $205,328 \mathrm{~km}^{2}$ according to the China Forest Administration website (http:// forest.ckcest.cn/, 12 December 2019).

To fight forest fires, the China Forestry Administration carries out a national program to define forest fire prevention and firefighting measures, including management of dead forest fuels. Research is being carried out in the Maoer Mountain forest ecosystem on live and dead fuel loads, and on the prediction model of fuel moisture content for fire risk management. In this regard, the present study addresses the second aspect of this research project to establish models for predicting moisture content of dead fuels in plantations on Maoer Mountain forest ecosystem. Dead fuels are defined as "recently and partially decomposed tree leaves, needles, twigs, grass, bark and branches, with no living tissue" (Simard 1968). They are divided into different time classes $(1,10,100$, and $1000 \mathrm{~h})$ as a function of their response time lag according to meteorological conditions, in particular relative humidity and temperature (Bradshaw et al. 1984).

Fuel load and moisture content, topography and wind speed are the main factors that control forest fires (Finney et al. 2010; Syphard et al. 2019), and fuel moisture is reported to be the most critical factor affecting fuel ignition (Possell and Bell 2013). Thus, identifying factors that affect fuel moisture content is crucial for fuel management, and fire prevention and suppression (Liu et al. 2013; Slijepcevic et al. 2015). As shown by Byram and Jemison (1943), fuel moisture content is a result of cumulative effects of past and current weather events. Moreover, Flannigan et al. (2016) showed that the moisture content of fuel is governed by a composite interaction between fuel characteristics, time, and environmental conditions such as rain and temperature. In general, factors that govern the dead fine fuel moisture content are relative humidity, temperature, precipitation, radiation, wind, as well as dew, soil humidity, soil temperature, slope, topography, aspect, and canopy density (Simard 1968; Nelson 2001; Chuvieco et al. 2004). For example, in rainless conditions, dead fine fuels have a moisture content less than $30 \%$, which corresponds to the saturation point of wood fibres when the relative humidity is $100 \%$. On the other hand, when fuels are exposed to rains, they store water in cell cavities and on their surface. In this case, their moisture content can reach 300\% (Slijepcevic et al. 2013).

Models of fuel moisture levels based on weather conditions have been developed using empirical, semi-physical or physical methods (Simard 1968; Catchpole et al. 2001; Nelson 2001; Wittich 2005; Matthews 2006; Matthews et al. 2010). Empirical models provide a useful approach for estimating the danger of wildfires, however they are limited in their ability to represent complex processes such as precipitation or variation in solar radiation, or to be extrapolated to other types of fuel (Matthews et al. 2010). Approximately twenty years ago, physical models were developed (Weise et al. 2005; Matthews et al. 2010) based on previously built models (Fosberg 1975; Viney and Hatton 1990) which included some relevant processes but not all. The model by Matthews (2006) is process-based to representing the flux of energy and water in a litter bed composed of three elements: litter, air, and water. The flux of heat and water of each of these three elements is calculated using equations based on six variables: litter moisture content ( $\mathrm{kg}$ of water per $\mathrm{kg}$ of dry litter), temperature of the free water on the litter surface, amount of water on litter surface ( $\mathrm{kg}$ of water per $\mathrm{m}$ of litter), litter temperature, air temperature, and relative humidity. In the physical model, the flux of heat, water and radiation between the litter and the atmosphere or soil is predicted by replacing variables of the flux of heat and water in the process-model by specified boundary conditions: relative humidity, temperature, precipitation, solar radiation, thermal radiation, wind speed, soil moisture, and soil temperature (Slijepcevic et al. 2013).

In this study, it is hypothesized that relative humidity, precipitation and temperature govern the moisture content of dead fine fuels in forest plantations of the Maoer Mountain forest ecosystem. The objective was to evaluate existing equilibrium moisture content models and to predict fuel moisture content using meteorological variables. The specific objectives were: (1) to choose the best equilibrium 
moisture content function that could be used during prescribed burning in plantations; (2) to develop a prediction model of fuel moisture content with meteorological variables; and, (3) to determine the relationship between fuel moisture content with meteorological and edaphic variables.

\section{Materials and methods}

\section{Study area}

A forest plantation in the Maoer Mountain forest ecosystem, $45^{\circ} 43{ }^{\prime} \mathrm{N}$ and $126^{\circ} 37^{\prime} \mathrm{E}$ in Harbin, Heilongjiang province at mean altitude of $255 \mathrm{~m}$ was selected (Fig. 1). The climate is cold and temperate with rainy summers. According to the Köppen and Geiger climate classification system, the area is a Dwb climate (humid continental). Yearly precipitation and average temperature are $649 \mathrm{~mm}$ and $2.7^{\circ} \mathrm{C}$, respectively. July is the hottest month with average temperatures of $21.8^{\circ} \mathrm{C}$, while January is the coldest with average temperatures of $-19.9^{\circ} \mathrm{C}$. The annual thermal amplitude is $41.7^{\circ} \mathrm{C}$, and the rain amplitude is $171 \mathrm{~mm}$. The parent material is granite bedrock and the soil is dark brown forest soil (Wang 2006). The primary forest was dominated by Korean pine mixed with deciduous species such as Betula spp., Larix spp., Populus spp., and Quercus spp. From the beginning of the twentieth century, the original forest has been largely destroyed by large-scale industrial logging by Russian and Japanese companies as well as by the Chinese government and replaced by secondary forest and plantations (Chen et al. 1982). At present, there are three main types of secondary forest distributed over various site conditions: a Mongolian oak forest on steep upper arid and infertile slopes, a mixed deciduous forest on well-drained fertile, gentle mid-slopes and a deciduous forest on gentle, moist, and fertile slopes. There are two dominant plantations of Pinus spp. and Larix spp. (Wang 2006). This study was carried out in forest plantations because models on fuel moisture content in these ecosystems have not as yet been established in the area, and both natural forests and plantations are subject to wildfires. Plantations of Pinus koraiensis Siebold and Zucc., Pinus sylvestris L., Larix gmelinii Rupr., and mixed Larix gmeliniiUlmus propinqua Koidz were selected because they produce large fuel loads that can easily ignite and spread fire. The fuel load and thickness estimates in Maoer Mountain forest ecosystem amount to $9.2 \pm 1.9 \mathrm{t} \mathrm{ha}^{-1}$ and $2.9 \pm 1.4 \mathrm{~cm}$ for $P$. koraiensis, $12.9 \pm 3.9 \mathrm{tha}^{-1}$ and $4.3 \pm 0.7 \mathrm{~cm}$ for L. gmelinii, and $8.5 \pm 0.5 \mathrm{tha}^{-1}$ and $2.3 \pm 1.4 \mathrm{~cm}$ for $P$. sylvestris (results not published). Forest plantations in Heilongjiang Province cover $40,420 \mathrm{~km}^{2}$, of which $87.4 \%$ are young and mid-aged.

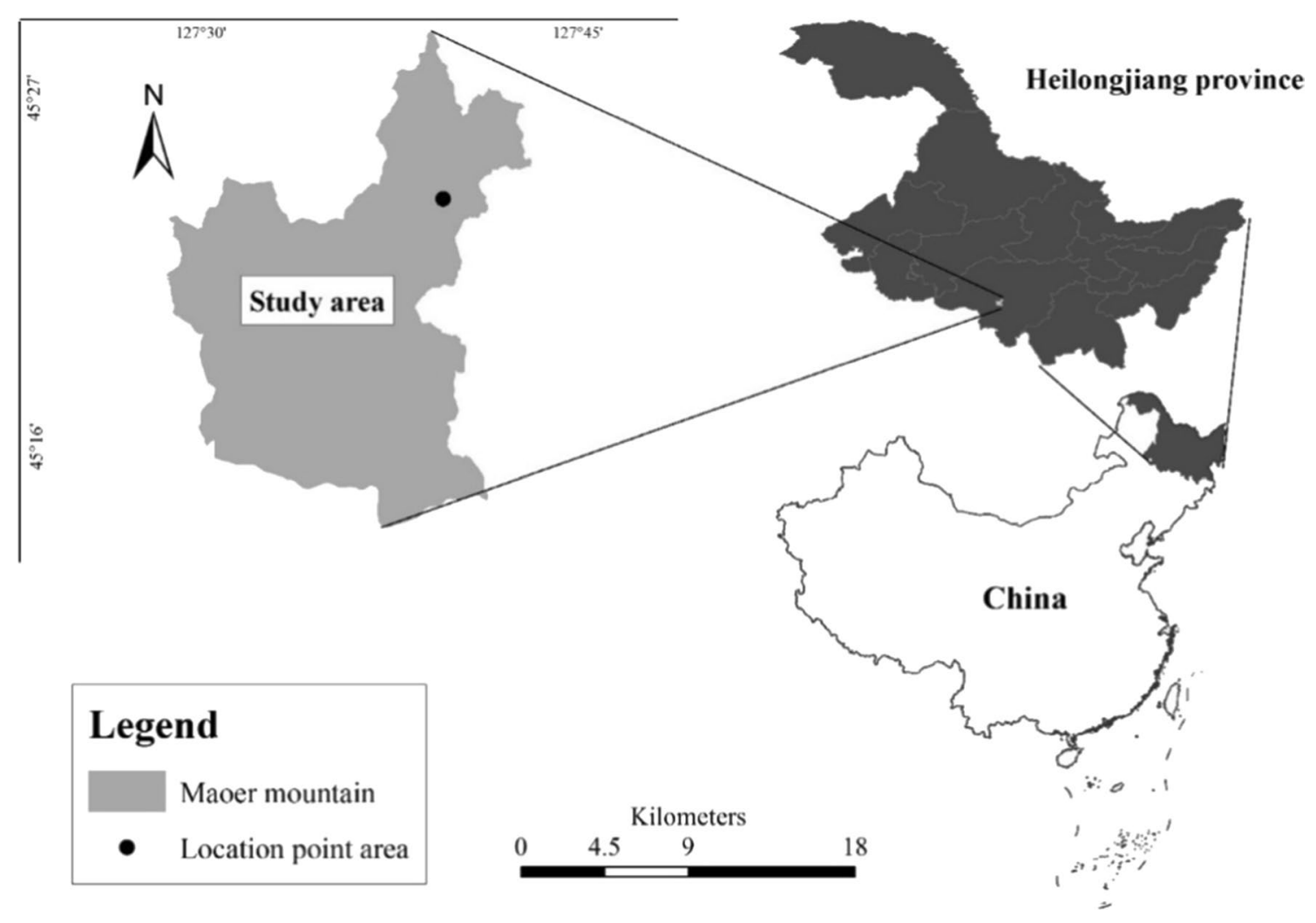

Fig. 1 Study location 
Coniferous plantations of L. gmelinii, P. koraiensis, P. sylvestris, Abies sibirica Ledeb. and A. nephrolepis (Trautv. ex Maxim.) Maxim. cover 24,560 $\mathrm{km}^{2}$, representing more than $60 \%$ of Heilongjiang's forest plantation area (Li Wenwu, n.d.). The fuel moisture content was measured in four different stands located between $127^{\circ} 39^{\prime} 39.5^{\prime \prime} \mathrm{E}$ and $45^{\circ} 24^{\prime}$ $13.75^{\prime \prime}$ N. More details about sampling plots are presented in Table 1.

\section{Fuel moisture content meter}

A fuel moisture content (FMC) meter consists of an automatic balance and a mini weather station operating with electrical energy produced by solar panel. It was designed by the Forest Fire Prevention Laboratory of the Northeast Forestry University and automatically measures fuel mass, air temperature, relative humidity, wind speed, solar radiation, and rainfall reaching the fuels on the ground as well as soil moisture and temperature. To check the accuracy of each FMC meter balance, a sample of dead fuel was weighed and its mass was compared to that obtained using the FMC meter in the field ( $0.01 \mathrm{~g}$ of error). Components of the FMC meter are shown in Fig. 2.

\section{Field sampling}

Data collection was carried out from September 23 to November 15, 2018. For each plantation, altitude, canopy density (shade), slope, aspect, height and diameter at breast height $(\mathrm{DBH})$ were recorded as they affect solar radiation, temperature and relative humidity on the soil surface under the canopy. In each stand, a $50 \times 50 \mathrm{~m}$ sampling plot

Table 1 Sampling plot description

\begin{tabular}{|c|c|c|c|c|c|c|c|c|c|c|c|}
\hline Plot & Species & $\mathrm{SP}(\%)$ & $\mathrm{D}(\mathrm{cm})$ & $\mathrm{H}(\mathrm{m})$ & $\mathrm{CD}(\%)$ & Slope $\left(^{\circ}\right)$ & Lth $(\mathrm{cm})$ & Alt (m) & Aspect & Longitude (E) & Latitude $(\mathrm{N})$ \\
\hline \multirow[t]{3}{*}{1} & Pinus koraiensis & 80 & 21.6 & 25 & 55 & 14 & 4.5 & 400 & NW & $127^{\circ} 39.92^{\prime}$ & $45^{\circ} 24.18^{\prime}$ \\
\hline & Populus davidiana Dode & 10 & 23.8 & 21 & & & & & & & \\
\hline & Betula platyphylla Sukaczev & 10 & 11.6 & 15 & & & & & & & \\
\hline \multirow[t]{3}{*}{2} & Pinus koraiensis & 50 & 8 & 10 & 40 & 13 & 7 & 380 & SW & $127^{\circ} 39.75^{\prime}$ & $45^{\circ} 24.20^{\prime}$ \\
\hline & Pinus sylvestris & 40 & 20 & 20 & & & & & & & \\
\hline & Betula platyphylla & 10 & 0 & 18 & & & & & & & \\
\hline \multirow[t]{2}{*}{3} & Larix gmelinii Rupr & 50 & 16.4 & 18 & 45 & 10 & 3.6 & 397 & SW & $127^{\circ} 39.60^{\prime}$ & $45^{\circ} 24.23^{\prime}$ \\
\hline & Ulmus propinqua Koidz & 50 & 12.6 & 8 & & & & & & & \\
\hline \multirow[t]{2}{*}{4} & Larix gmelinii Rupr & 75 & 18 & 25 & 60 & 16 & 8.5 & 389 & W & $127^{\circ} 39.45^{\prime}$ & $45^{\circ} 24.30^{\prime}$ \\
\hline & Picea asperata Nakai & 25 & 10 & 8 & & & & & & & \\
\hline
\end{tabular}

$S P$ species composition, $D$ tree diameter, $H$ tree height, $C D$ canopy density, $L t h$ litter thickness; Alt altitude; $N W$ northwest, $S W$ southwest, $W$ west

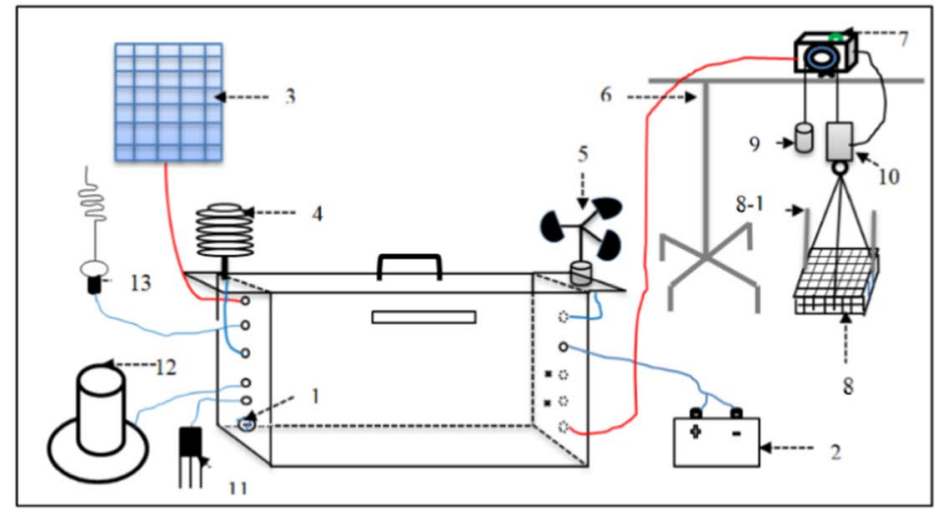

(a)

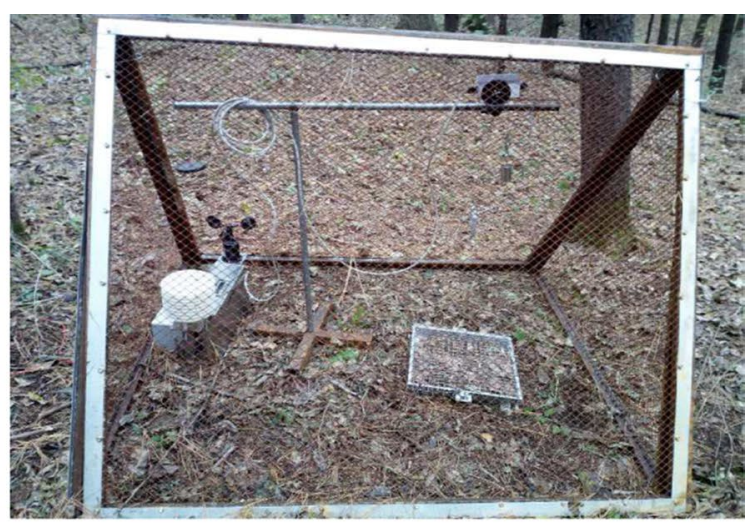

(b)
Fig. 2 FMC-Meter components (a), 1: on/off; 2: battery; 3: solar panel; 4: air temperature and humidity sensor (AM2305, Guangzhou Lexiang Electronics Co., Ltd.); 5: anemometer wind speed sensor (YGC-FS-SY-M, Wuhan Chenyun Technology Co., Ltd.); 6: stand; 7: illuminance sensor (BCE, Huai' an Lankong Electronics Co., Ltd.);
8: basket of fuel $(30 \mathrm{~cm} \times 30 \mathrm{~cm} \times 6 \mathrm{~cm}) ; 8-1$ : guide rail (controls the basket's position during weighing); 9: marked mass; 10: automatic balance; 11: soil temperature and moisture sensors (RS485, Jinan Jianda Renke Co., Ltd.); 12: rain gauge; 13: SIM CARD (GSM,1000-1800). On the right (b) is the FMC meter in the field 
was established and five sampling points were randomly installed where fuels were evenly distributed. Samples of dead leaves, needles and small twigs $<3 \mathrm{~mm}$ (Burgan and Rothermel 1984) were collected at random points (Schunk et al. 2017) and placed in the FMC $30 \mathrm{~cm} \times 30 \mathrm{~cm} \times 6 \mathrm{~cm}$ basket at each sampling point, and oven dried for $24 \mathrm{~h}$ at $105{ }^{\circ} \mathrm{C}$. Samples were then weighed and placed back in the plot on the ground (duff layer) in a basket attached to the FMC meter scale (Fig. 2). To avoid disturbance of samples, a protective $1-\mathrm{cm}$ mesh was put around the FMC meter. The initially sampled and dried fuels were kept on the FMC meter throughout the study period (i.e., there was no repeated manual sampling).

To analyse the variations in fuel moisture content, halfhourly meteorological and soil data provided by the FMC meter in different sampling plots were recorded. The FMC meter automatically recorded fuel weight, relative humidity, wind speed, solar radiation and temperature. Data were shared through hotspot from the FMC meter to an Android cell phone on which the fmcmeter software was installed (see supplementary Appendix 1). As a rain gauge and soil temperature and moisture sensors were not operational throughout the data collection, data were provided by the Global Ecology Laboratory of the Northeast Forestry University. This laboratory measures soil temperatures and humidity at a 5-cm depth by CS107L sensor (Campbell Company) connected to an automatic acquisition system (CR23X, Campbell).

\section{Data analysis}

The gravimetric method was used as it is regarded as most reliable, inexpensive, and accurate. It involves taking fuel samples of a predetermined size (fine, mid-size, large), and oven drying these samples (Pippen 2008). The fuel moisture content (FMC) determines the amount of water in the sample by calculating the quotient of difference between the wet mass and the dry mass (Slijepcevic et al. 2015) using the following function:FMC $=\frac{\mathrm{W}_{\mathrm{w}}-\mathrm{W}_{\mathrm{d}}}{\mathrm{W}_{\mathrm{d}}} \times 100$

$F M C=\frac{W_{w}-W_{d}}{W_{d}} \times 100$

where $W_{w}$ is the fresh weight and $W_{d}$ the drying weight.

Various methods have been used for estimating fuel moisture content (Schroeder and Buck 1970). Among these, two kinds of models were developed in this study: the equilibrium moisture content model and the meteorological regression model. The random forest model was developed using the train function in randomForest and e1071 packages, and a generalized additive model using the gam function in $m g c v$ package in RStudio version 1.1.453.0 (RStudio Team 2018 ) with generalized cross-validation (GCV) or restricted maximum likelihood (REML) processes. Graphs of fuel moisture content variation were drawn with OriginPro2018 (Origin Lab, Northampton, MA, USA).

\section{Test and validation of selected equilibrium moisture content models}

Nelson (1984) model was used because it is widely accepted and incorporated into many physical models (Catchpole et al. 2001; Wittich 2005; Matthews 2006). Van Wagner and Pickett (1985)'s model was tested because it had been built using coniferous fuels and its use is still operational. Simard (1968) and Nelson and Hiers (2008) models have not been tested because they are weak predictors of fine fuel moisture content (Pippen 2008). In addition, models of Catchpole et al. (2001), Matthews (2006), and Wittich (2005) have not been tested because they are no longer operational. Other models not mentioned here were not tested because their operational use is considered unclear (Pippen 2008). Thus, among all of these functions only the ones of Nelson (1984) and Van Wagner and Pickett's (1985) were adapted using temperature and relative humidity. The following functions mathematically represent these models:

(a) Nelson (1984) equilibrium moisture content response to environmental factors is defined as:

$$
E M C=\alpha+\beta \log \Delta G=\alpha+\beta \cdot \log \left(-\frac{R T}{m} \log H\right)
$$

where $R$ is the universal gas constant $\left(8.314 \mathrm{~J} \mathrm{~K}^{-1} \mathrm{~mol}^{-1}\right)$; $T$ is the ambient air temperature $\left({ }^{\circ} \mathrm{K}\right) ; H$ is the air relative humidity (\%); $m$ is the $\mathrm{H}_{2} \mathrm{O}$ relative molecular mass $\left(18 \mathrm{~g} \mathrm{~mol}^{-1}\right) ; \alpha, \beta$ are the parameters to be estimated.

(b) Van Wagner and Pickett (1985) model is:

$$
\begin{aligned}
E M C= & 0.942 H^{0.679}+0.000499 \exp (0.1 H) \\
& +0.18(21.1-T)(1-\exp (-0.115 H)
\end{aligned}
$$

where $H$ is the relative humidity and $T$ the temperature $\left({ }^{\circ} \mathrm{C}\right)$.

To evaluate the equilibrium moisture content models, the root-mean square error (RSME) and mean absolute error (MAE) were used to choose the best model.

\section{Meteorological regression method}

Studies on fuel moisture content prediction have been conducted in natural forests in northeast China (Zhang et al. 2014; Sun et al. 2018). However, these studies have used an empirical method whose model's extrapolation are often limited. The present study used a physical method for developing predicting models that could be extrapolated to other 
sites or other types of fuels, taking into account the relevant processes of material, energy and heat flux between litter and atmosphere or soil. The prediction of fuel moisture content was developed using a random forest model and a generalized additive model.

Random forest model was selected as it is highly accurate, robust to outliers and noise, faster than bagging or boosting, and most interpretable (Breiman 2001). Variables of the best model were defined by combining the variable importance score to the number of variables (see "mtry") in the best model. For each model fitted, the optimal number of significant predictors was identified by "mtry" parameter with the 10-folds cross-validation method. The best model was determined by the optimal number of significant predictors, the lowest root-mean square error and mean absolute error, and the highest value of the adjusted $\mathrm{R}^{2}$.

Generalized additive model (GAM) was fitted to predict FMC models as it describes the relationship between dependent and independent variables without prejudging the issue by selecting any particular parametric method (De Leeuw 2009). GAMs cover an extensive range of models, such as multiple linear, generalised linear, and mixed effect models (Wood 2018). They extend linear and generalized linear models to include smooth functions of independent variables with smoothness determined by either a parameter that directly controls the curve smoothness or the estimated predictive accuracy. They are determined by the following function:

$g\left(\mu_{i}\right)=s_{0}+\sum_{i=1}^{p} s_{i}\left(X_{i}\right)+\sum_{i . j=1}^{p} s_{i, j}\left(X_{i . j}\right)+\varepsilon$

where $\boldsymbol{\mu}_{\boldsymbol{i}}$ is the mean of the dependent variable, $\boldsymbol{s}_{\boldsymbol{0}}$ the parametric coefficient, $s_{i}$ the smooth functions defining the additive component, and $X_{i}$ the independent variables; $\operatorname{si}\left(X_{i}\right)$ is the smooth terms, $s_{i . j}\left(X_{i} \cdot X_{j}\right)$ the tensor product terms, and $\varepsilon$ the error. The smooth terms are text series giving the names of the covariates whose term is a function. The tensor product smoothers result from smoothing interaction of any or all of covariates. They are a natural way to represent smooth terms interaction in regression models as they are invariant compared to units in which covariates are measured, thus avoiding the need for arbitrary decisions regarding relative scaling of variables (Wood et al. 2013). They are suitable for models of variables with different units.

Generalized additive models were defined using a Gaussian family and an identity link function. For each FMC model, we first ran the model including all covariates, then consecutively removed covariates with the highest concurvity until all covariate concurvity estimates were $<0.4$ (Lydersen et al. 2019). This restricted the effect of correlation between covariates in the model. Model prediction accuracy was determined by the generalized cross-validation (GCV) and restricted maximum likelihood (REML) methods. With the GCV, each sample was randomly divided into $\mathrm{k}$ (unfixed parameter, 10 in this case) equal-sized subsamples. One of ten subsamples was retained as validation data to test the model, and the nine remaining subsamples were used as training data. The cross-validation process was repeated ten times and resulted in a single estimation. The benefit of the GCV is that all observations are used for both training and validation (Golub et al. 1979). Selection of best models was made with the lowest GCV/REML and AIC, and highest adjusted $R^{2}$.

\section{Results}

\section{Validation test of selected equilibrium moisture content models}

Nelson (1984) and Van Wagner and Pickett (1985) models were tested with field data (temperature and relative humidity) to ensure their validity during controlled burning. After model fitting, only the Nelson's model showed good accuracy, with RMSE and MAE less than 1\%, and was validated as suitable for prescribed burning in Maoer Mountain forest ecosystems. The Van Wagner and Pickett (1985) model was less accurate, with RMSE and MAE $\geq 5 \%$ (Table 2).
Table 2 Accuracy of selected equilibrium moisture content models; where b0, b1, b2 represent the parametric coefficients

\begin{tabular}{llllllll}
\hline Forest species & Type of model & \multicolumn{2}{l}{ Parameters } & & \multicolumn{2}{l}{ Errors } \\
\cline { 3 - 4 } & & $b_{0}$ & $b_{1}$ & $b_{2}$ & & RMSE (\%) & MAE (\%) \\
\hline Pinus koraiensis & Nelson & -760 & -5.85 & - & & 0.8 & 0.6 \\
& Van Wagner & 0.942 & 0.000499 & 0.017 & 6.5 & 5.3 \\
Pinus koraiensis & Nelson & -325.6 & -15.64 & - & & 0.6 & 0.5 \\
Pinus sylvestris & Van Wagner & 0.942 & 0.000499 & 0.017 & 8.2 & 6.8 \\
Larix gmelinii & Nelson & -282.4 & -7.07 & - & & 0.7 & 0.6 \\
Ulmus propinqua & Van Wagner & 0.942 & 0.000499 & 0.017 & 6.3 & 5.0 \\
Larix gmelinii & Nelson & -456.1 & -23.75 & - & & 0.8 & 0.7 \\
& Van Wagner & 0.942 & 0.000499 & 0.017 & & 21.0 & 19.6 \\
\hline
\end{tabular}




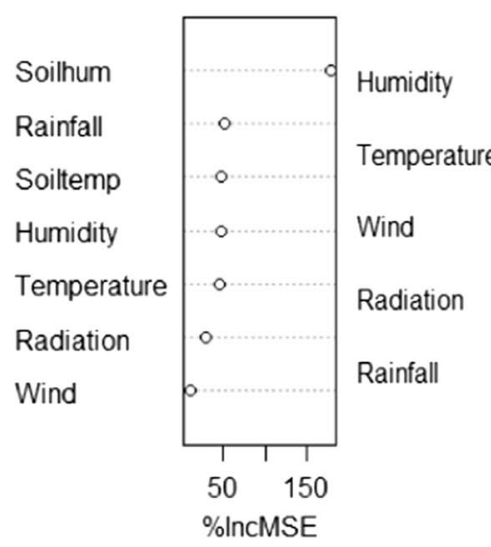

(a)

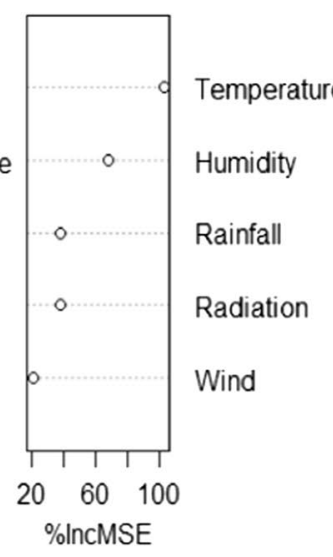

(b)

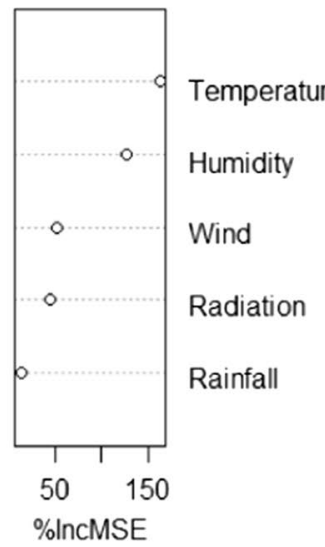

(c)

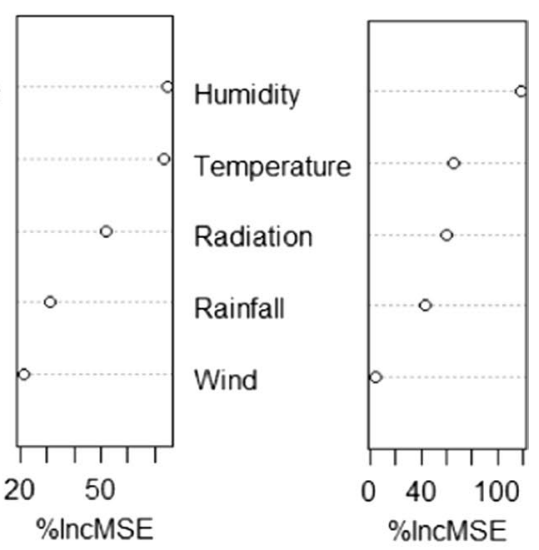

(d)

(e)

Fig. 3 Variable importance measures with the random forest method based on mean squared error (i.e., error of a tree, in abscise). The increase average error of a tree (MSE for regression) is the most widely used importance score as a given variable in the random forest framework; (a) and (b) represent the variable importance plots pro-

\section{Ranking importance of variables using the random forest method}

Plots of variable importance were built with the random forest method (Fig. 3). In the P. koraiensis plantation, two graphs, (a) one showing the variable importance of the model built with both meteorological and edaphic variables, and (b) the other showing the variable importance in the model with meteorological variables. Observations revealed that the soil moisture content significantly affected the FMC (Fig. 3a). In all plantations (without considering

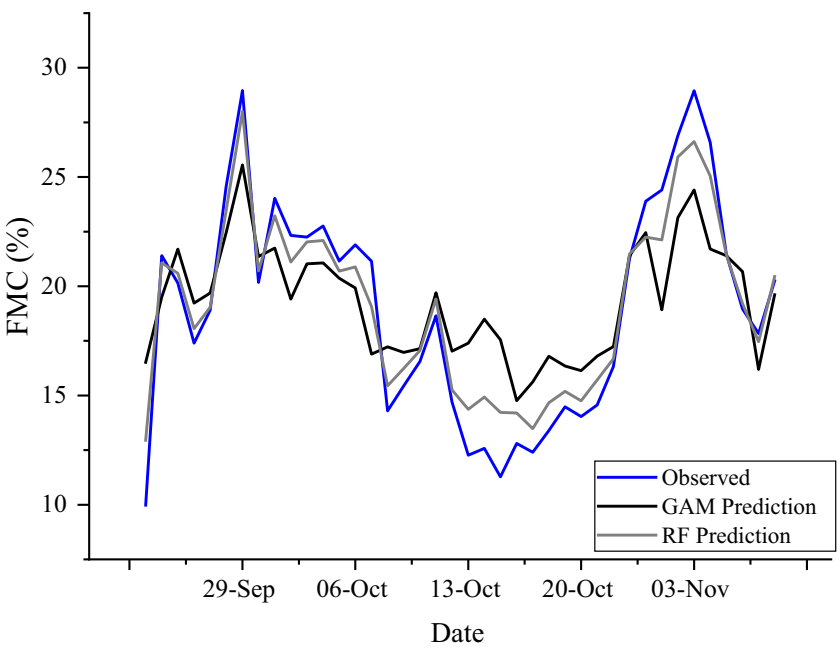

(a) duced by the model in the $P$. koraiensis plantation with and without edaphic parameters; (c) represents the variable importance plot in the mixed $P$. sylvestris and $P$. koraiensis plantation, (d) in mixed the $L$. gmelinii - U. propinqua plantation, and (e) in the L. gmelinii plantation

soil variables), relative humidity and temperature were the most important variables that affected the FMC.

\section{Fuel moisture content variation}

Temporal changes in FMC were due to different factors. After placing the fuels back into the FMC meter, a sudden increase had been observed with $P$. koraiensis fuel (Fig. 4) and mixed P. sylvestris-P. koraiensis fuel (Fig. 5a) as it had rained in the evening of that day. In the L. gmelinii$U$. propinqua planation (Fig. $5 \mathrm{~b}$ ) and L. gmelinii plantation (Fig. 6), samples were put back one day after the rainfall

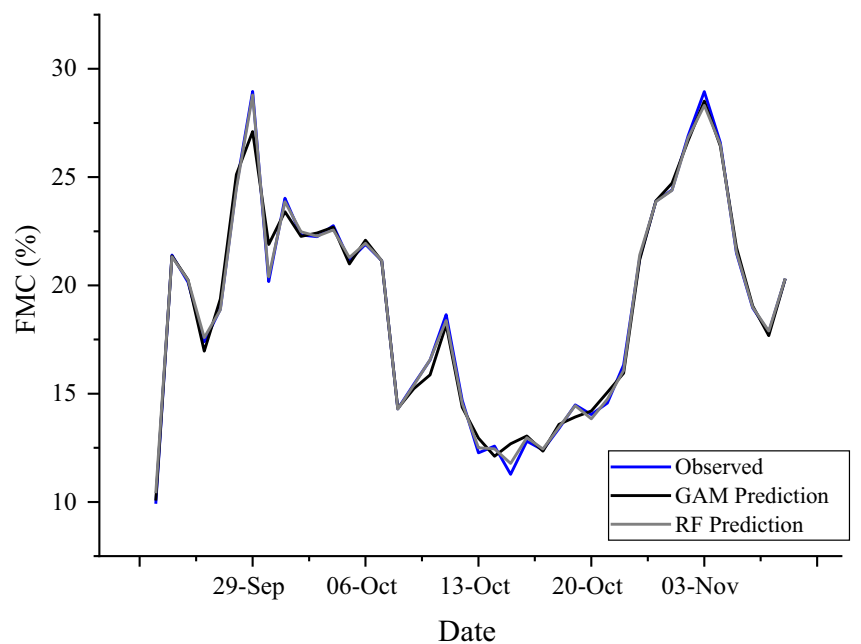

(b)

Fig. 4 Observed and predicted FMC in P. koraiensis plot in (a) model fitted with meteorological variables, (b) model fitted with meteorological and soil variables 


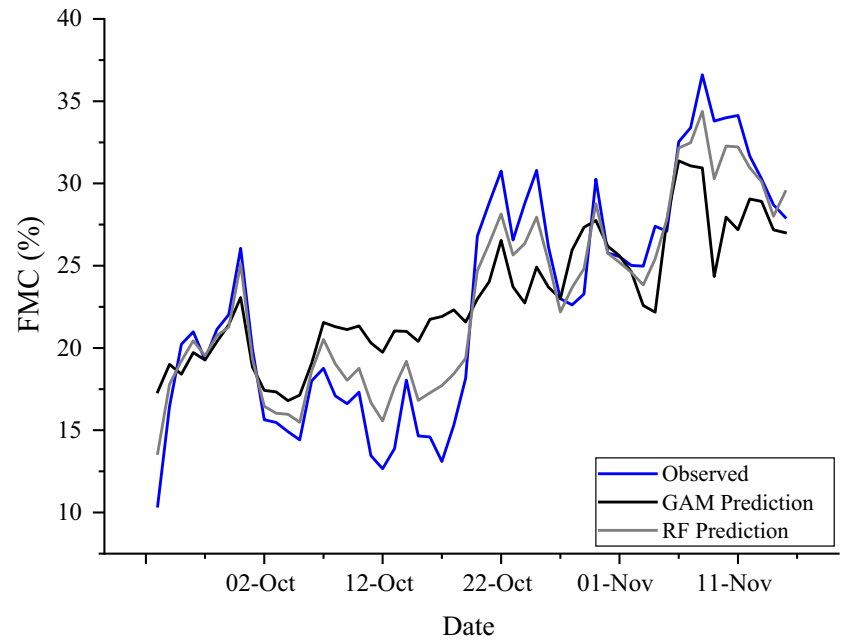

(a)

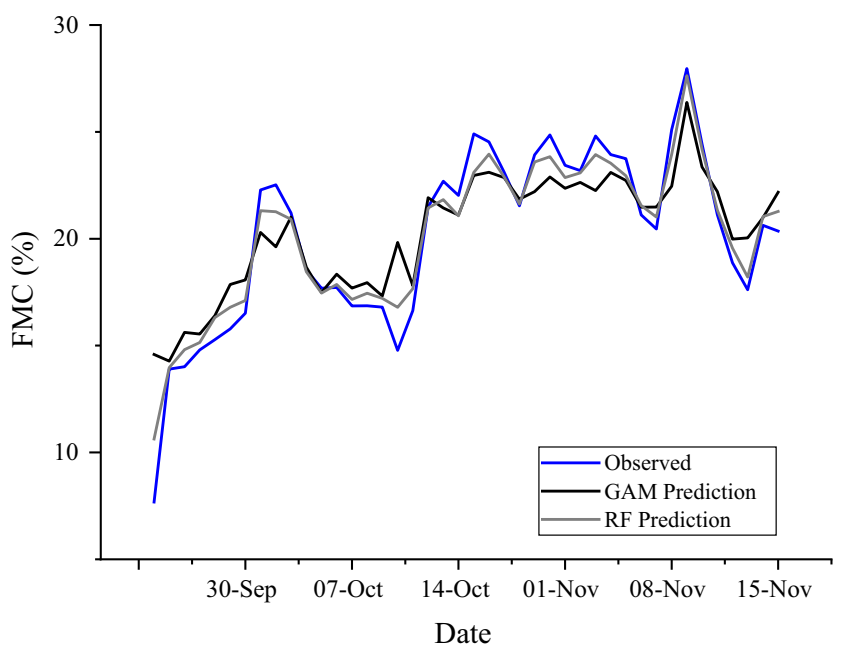

(b)

Fig. 5 Observed and predicted FMC in (a) P. sylvestris and P. koraiensis plantation; (b) L. gmelinii and U. propinqua plantation

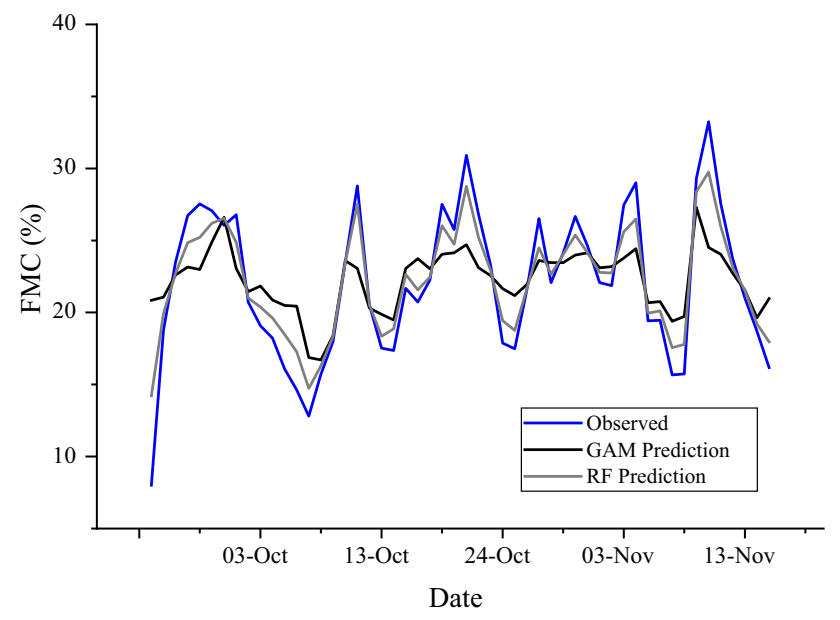

Fig. 6 Observed and predicted FMC in the Larix gmelinii plantation and FMC had gradually peaked in the last three days of September. Subsequently, for the period from October 1 to October 20, FMC values were generally below 20\%, with minimum values around October 15. The increase in FMC beyond October 20 would be related to snowmelt, in addition to rainfall, temperature, relative humidity, solar radiation, wind speed, soil moisture, and temperature measured in this study (Figs. 4, 5, 6). Dahurian larch fuels had a higher water holding capacity than pine fuels. In the same way that these fuels absorbed rain water during rainy periods, they gradually lose it compared to pine fuels which were sensitive to small changes in temperature or sunshine. The solar radiation contributed considerably to the FMC in pine plantations, and wind speed significantly impacted the FMC (GAM) only in mixed the L. gmelinii-U. propinqua plantation due to its proximity to an open area. Minimum and

Table 3 Minimum and maximum values of parameters in the different plots

\begin{tabular}{|c|c|c|c|c|c|c|c|c|c|}
\hline & Fuel species & Temp $\left({ }^{\circ} \mathrm{C}\right)$ & $\mathrm{H}(\%)$ & Rain (mm) & Wind $\left(\mathrm{m} \mathrm{s}^{-1}\right)$ & Radiation $\left(\mathrm{W} \mathrm{m}^{-2}\right)$ & Soil temp $\left({ }^{\circ} \mathrm{C}\right)$ & Soil h. (\%) & FMC (\%) \\
\hline \multirow[t]{4}{*}{ Min } & Pinus koraiensis & -3.1 & 34.9 & 0 & 0 & 0 & 1.659 & 21.5 & 1.687 \\
\hline & P. sylvestris-P. koraiensis & -10 & 27.0 & 0 & 0 & 0 & - & - & 0.962 \\
\hline & $\begin{array}{l}\text { Larix gmelinii-Ulmus } \\
\text { propinqua }\end{array}$ & -9.9 & 23.1 & 0 & 0 & 0 & - & - & 0.965 \\
\hline & Larix gmelinii & -10.6 & 35 & 0 & 0 & 0 & - & - & 0.968 \\
\hline \multirow[t]{4}{*}{$\operatorname{Max}$} & Pinus koraiensis & 20.2 & 86.7 & 2.3 & 2.25 & 537.9 & 12.71 & 28.43 & 35.731 \\
\hline & P. sylvestris $-P$. koraiensis & 22.3 & 96.8 & 2.8 & 2.33 & 822.0 & - & - & 37.928 \\
\hline & $\begin{array}{l}\text { Larix gmelinii-Ulmus } \\
\text { propinqua }\end{array}$ & 25.5 & 90.1 & 2.5 & 2.95 & 1062.0 & - & - & 29.877 \\
\hline & Larix gmelinii & 21.4 & 95.7 & 2.8 & 0.80 & 910.8 & - & - & 38.717 \\
\hline
\end{tabular}


maximum values of parameters are presented in Table 3 . Meteorological records at the time of FMC sampling varied from $-10.6{ }^{\circ} \mathrm{C}$ to $25.5^{\circ} \mathrm{C}$ for temperature, $23.1-96.8 \%$ for relative humidity, zero to $2.8 \mathrm{~mm}$ for rainfall, zero to $2.95 \mathrm{~m} \mathrm{~s}^{-1}$ for wind speed, and zero to $1062 \mathrm{~W} \mathrm{~m}^{-2}$ for solar radiation. Soil variables varied from $1.7^{\circ} \mathrm{C}$ to $12.7^{\circ} \mathrm{C}$ for temperature and $21.5-28.4 \%$ for 1 humidity. The max value of FMC (38.7\%) was observed in the L. gmelinii plantation and was related to higher values of relative humidity, low wind speeds (Table 3), canopy density and litter thickness (Table 1).

Comparison between Fig. $4 \mathrm{a}$, b which present the graphs of observed and predicted values of fuel moisture content in the P. koraiensis plantation shows that integration of soil humidity and temperature increases the models (RF and GAM) accuracy.

\section{Model validation}

To evaluate the accuracy of the random forest model, the variable importance score and cross-validation method were used. Random forest models showed that temperature and relative humidity were the most important factors affecting fuel moisture content. For all selected models, the RMSE and MAE values were below 5\%. The model fitted with meteorological and soil variables (in the $P$. koraiensis plantation) was reasonably accurate (lower error values and a high value of $\mathrm{R}^{2}$-adj=0.87) compared to the model fitted with meteorological variables only for which adjusted $\mathrm{R}^{2}$ equalled $48 \%$. In all plantations, models fitted with meteorological variables had RMSE and MAE vales lower than 5\% and adjusted $\mathrm{R}^{2}$ between 39 and $63 \%$ (Table 4 ).

GAM prediction showed that temperature, relative humidity and rainfall were the most important drivers of fuel moisture content. The estimated degrees of freedom and model accuracy parameters in all plantations are presented in Table 5 (for generalized cross-validation method) and in Table 6 (for restricted maximized likelihood method). Beyond the combined effect of temperature, rainfall and relative humidity, solar radiation or wind speed effect was also significant in some sites. Models fitted with soil variables (without soil variables) had explanatory power that varied from $32.8 \%$ (31.7\%) to $50.0 \%$ (48.6\%). However, in the $P$. koraiensis plantation where soil variables were measured, GAM explained $82.8 \%$ of FMC variation in the model fitted with both meteorological and soil variables; however, it explained only $39.1 \%$ (36.3\%) of the FMC variation in the model fitted with only meteorological variables. Fuel moisture content varied mainly with the combined effect of soil moisture, rainfall, soil temperature, and secondly with the combined effect of relative humidity and temperature as well as solar radiation. The best model in the P. sylvestris and $P$. koraiensis plantation included both the combined effect of relative humidity, temperature and rainfall, and the combined effect of temperature and radiation and explained $38.1 \%$ (36.8\%) of the deviance. The best model in the $L$. gmelinii and $U$. propinqua plantation included both the combined effect of relative humidity, temperature and rainfall and the combined effect of temperature and wind, and explained $50.1 \%$ (48.6\%) of the deviance. The best model in the L. gmelinii plantation had particularly low explanatory power, accounting for $32.8 \%$ (31.7\%) of the deviance. Comparing both methods using AIC, GCV accuracy was better than REML. Significant differences between models fitted with both meteorological and soil variables, and models fitted with only meteorological variables explained sufficiently the contribution of soil moisture and temperature on fuel moisture content.

\section{Discussion}

An overall outlook was made on the main weather factors affecting dead fine fuel moisture levels in Maoer Mountain forest plantations. Selected equilibrium moisture content (EMC) models were tested, importance score of variables measured to identify the best attributes influencing fuel moisture content, and prediction models of FMC developed and adopted.

Nelson's (1984) model predicted the equilibrium moisture content better than the Van Wagner and Pickett (1985)
Table 4 Random forests model accuracy

\begin{tabular}{lllllll}
\hline Plantation species & $\mathrm{Nv}$ & $\mathrm{m} t \mathrm{y}$ & Predictors & $\mathrm{RMSE}$ & $\mathrm{MAE}$ & $\mathrm{R}^{2}$-adj \\
\hline Pinus koraiensis* $^{*}$ & 7 & 4 & $S_{m,}, S_{t}, H, T$ & 1.96 & 1.43 & 0.87 \\
Pinus koraiensis & 5 & 3 & $H, T, W$ & 3.39 & 3.03 & 0.48 \\
P. sylvestris and P. koraiensis & 5 & 3 & $T, H, R_{f}$ & 4.93 & 3.68 & 0.50 \\
L. gmelinii and U. propingua & 5 & 3 & $T, H, W$ & 2.54 & 1.81 & 0.63 \\
Larix gmelinii & 5 & 3 & $H, T, R$ & 4.73 & 3.51 & 0.39 \\
\hline
\end{tabular}

*Identifies the model fitted with meteorological and soil variables, $n v$ the number of explanatory variables in the fitted model; mtry determines the number of predictors in the selected models; $S_{m}$. soil moisture; $S_{t}$. soil temperature; $H$ relative humidity, $T$ air temperature; $W$ wind speed; $R_{f .}$ rainfall; $R$ solar radiation 


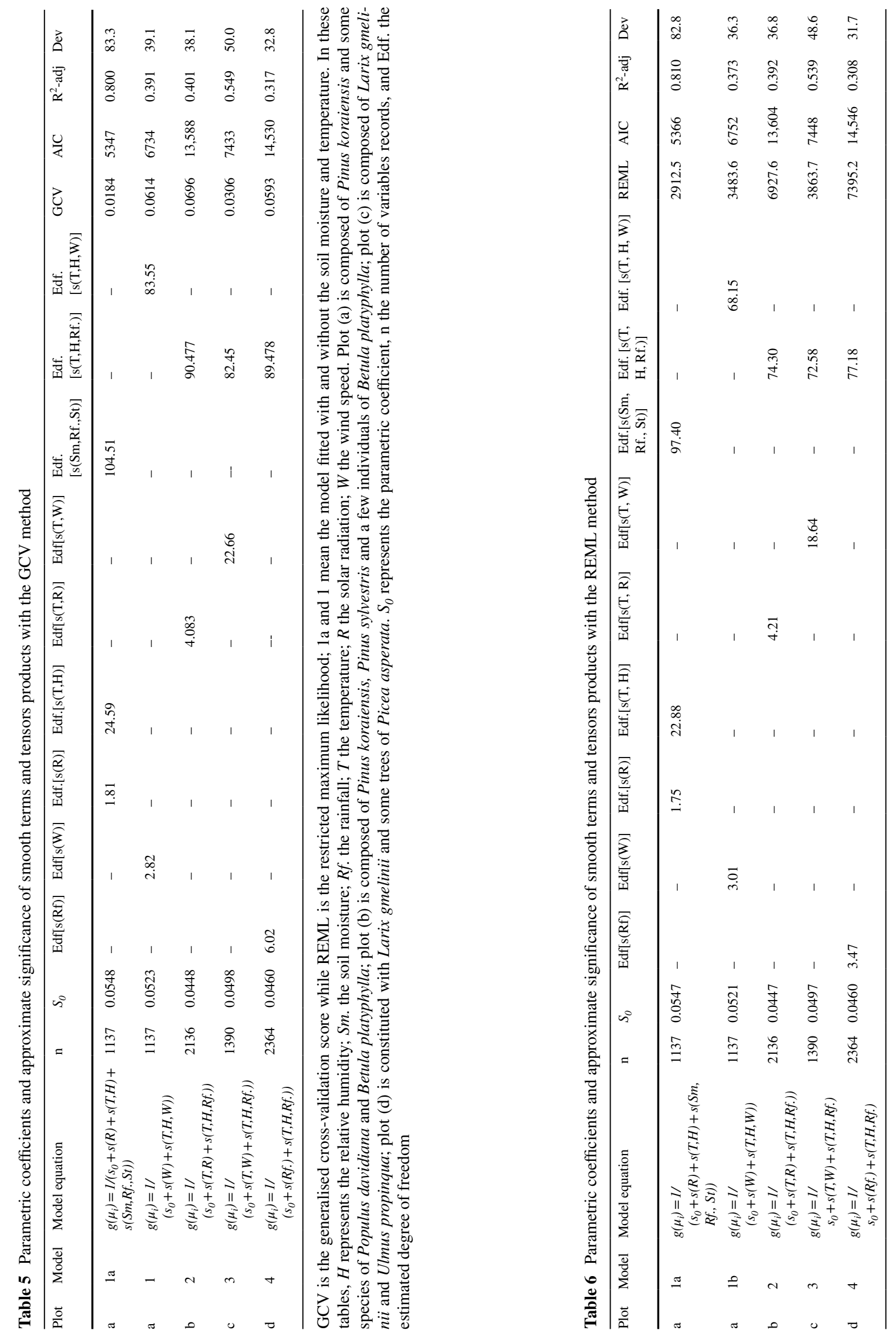


model. However, the EMC model is useful during predominantly dry conditions. In all sampling sites, the RMSE and MAE values of Nelson's (1984) model were lower than 1\%, whereas for Van Wagner and Picket's (1985) model, these values were above $5 \%$, and even reached $21 \%$. Our results are consistent with previous findings of Sun et al. (2015). The relatively good accuracy of Nelson's (1984) model may be explained by the fact that it is a semi-physical model, whereas Wagner and Picket's (1985) model is an empirical one (Yu et al. 2018). The Nelson (1984) model accuracy was consistent with what was suggested by Pippen (2008), stating that a better model of fuel moisture content must have precision in the range of 1-2\% accuracy to ensure its effectiveness in fire risk management. This concurs with $\mathrm{Hu}$ et al. (2016) who found the EMC method suitable for predicting FMC on small forest scales.

The generalized additive model showed that the combined effects of temperature, relative humidity and precipitation on FMC was significant. This confirms our hypothesis that rainfall, relative humidity and temperature are the main drivers affecting fuel moisture contents in P. koraiensis, $P$. sylvestris, L. gmelinii, and mixed L. gmelinii-U. propinqua plantations on Maoer Mountain. Solar radiation or wind speed were additional predictors in the model. Their effect would be influenced by aspect, canopy density, litter thickness, and altitude. The random forest and generalized additive models responded differently to rainfall. The RF model appeared to provide more precision than GAM however, it underestimated the rainfall effect on fuel moisture content. In addition, because our models were developed with data taken on the surface where fuels are located provides greater accuracy compared to models developed with data from weather stations far from sampling sites. These results are consistent with Sen and Wan-long (2014) showing that precipitation strongly affects FMC and share a number of similarities with Zhang et al. (2014) and Chae et al. (2017) that showed that fuel moisture content is firmly related to rainfall and relative humidity, and with results of Bilgili et al. (2019) that showed that FMC correlates well with relative humidity and temperature for all types of fuels. The effect of wind speed on FMC was significant only in the $L$. gmelinii-U. propinqua plantation due to its proximity to an open area. However, its effect on FMC in other plantations was not significant, in agreement with Larsen (2015) who showed that the influence of wind speed on the moisture content of fuel is not apparent, mainly because the canopy of trees reduces wind speed or prevents it from reaching fuels on the soil surface. Although soil moisture and temperature were measured in one plantation, results show that their effect on fuel moisture was significant and are consistent with Krivtsov et al. (2008) and Matthews (2014) In addition to the variables considered in this study, slope, aspect, and altitude should be incorporated in future models for a better understanding of environmental conditions on fuel moisture contents in Heilongjiang forest ecosystems.

In contrast to Byram and Jemison's (1943) method that developed a fuel moisture content model with current and past weather data, this study used current data because past data are documented on a daily average, while this study developed models with half-hour data. Although the models established in this study appear to be weak using current data, they are preliminary tools for monitoring moisture content of fuel in a shorter time interval. The use of Byram and Jemison's (1943) method also has drawbacks because its results are based on historical data while its application should relate to future forecast analysis. However, a comparative study on daily averages of current and past data will be carried out to evaluate the trend, especially since climate change is hypothesized to impact meteorological variables. Our results may have limitations for operational use. The first is that data in this study were tested in one season, thus giving a partial view of FMC variations. The second is that fire managers will use data of weather stations that are often in open areas far from local sites compared to measurements taken with an FMC meter in the field under tree canopies. In the next step in data collection, outdoor meteorological data will be included to make the study more applicable. The third limitation is that both random forest and generalized additive models do not have a mathematical formula that can be used without statistical software. But a general linear model could be fitted with significant variables, although its precision is lower than that of both.

\section{Conclusion}

In this study, the equilibrium moisture content function and meteorological regression method were used to predict the moisture content of dead fine surface fuels in plantations in the Maoer Mountain forest ecosystem. To achieve this, plantations of pine and Dahurian larch were selected as they produce large fuel loads that constitute a significant factor for forest fire management. Variable importance score was determined, and models were established. Nelson's (1984) function was validated for prescribed burning as it provided the best accuracy for predicting fuel moisture levels in sampled plantations. As expected from our hypothesis, the effect of temperature, relative humidity and rainfall on FMC was significant. Prediction model accuracy was substantially upgraded by including soil variables. The accuracy of the random forest model and generalized additive model was similar, however the accuracy of the random forest model was slightly higher but underestimated the effect of rainfall on FMC. The data used in this work were tested in one season, thus giving a partial view of fuel moisture content variations. Further investigations on dead and live fuels are needed to estimate fuel moisture contents of typical forest plantations in the region. 
Acknowledgements We sincerely thank Professor Wang Chuankuan, Director of the Global Ecology Laboratory at the Northeast Forestry University for providing us rainfall, soil moisture and temperature data. We are grateful to Dr Christian Schunk, safety engineer at the Technical University of Munich, and Mr Alen Slijepcevic, Australian Deputy Chief Officer-Bushfire for their collaboration and contribution. We are particularly grateful to constructive comments of the anonymous referees.

Open Access This article is licensed under a Creative Commons Attribution 4.0 International License, which permits use, sharing, adaptation, distribution and reproduction in any medium or format, as long as you give appropriate credit to the original author(s) and the source, provide a link to the Creative Commons licence, and indicate if changes were made. The images or other third party material in this article are included in the article's Creative Commons licence, unless indicated otherwise in a credit line to the material. If material is not included in the article's Creative Commons licence and your intended use is not permitted by statutory regulation or exceeds the permitted use, you will need to obtain permission directly from the copyright holder. To view a copy of this licence, visit http://creativecommons.org/licenses/by/4.0/.

\section{References}

Beach RH, Sills EO, Liu TM, Pattanayak S (2010) The influence of forest management on vulnerability of forests to severe weather. In: Pye, John M.; Rauscher, H. Michael; Sands, Yasmeen; Lee, Danny C.; Beatty, Jerome S., tech. (Eds.) 2010. Advances in threat assessment and their application to forest and rangeland management. Gen. Tech. Rep. PNW-GTR-802. Portland, OR: US Department of Agriculture, Forest Service, Pacific Northwest and Southern Research Stations: 185-206

Bilgili E, Coskuner KA, Usta Y, Goltas M (2019) Modeling surface fuels moisture content in Pinus brutia stands. J For Res 30:577-587

Bradshaw LS (1984) The 1978 national fire-danger rating system: technical documentation. US Department of Agriculture, Forest Service,Intermountain Forest and Range Experiment Station, p 44

Breiman L (2001) Random forests. Mach learn 45(1):5-32

Burgan RE (1984). Behave: fire behavior prediction and fuel modeling system, fuel subsystem (Vol. 167). Intermountain forest and range experiment station, forest service, US Department of Agriculture. https://doi.org/https://doi.org/10.1017/CBO97 81107415324.004

Byram GM, Jemison GM (1943) Solar radiation and forest fuel moisture. J Agric Res 67:149-176

Carnus JM, Parrotta J, Brockerhoff E, Arbez M, Jactel H, Kremer A, Lamb D, O'Hara K, Walters B (2006) Planted forests and biodiversity. J For 104:65-77

Catchpole EA, Catchpole WR, Viney NR, McCaw WL, MarsdenSmedley JB (2001) Estimating fuel response time and predicting fuel moisture content from field data. Int J Wildl Fire 10:215-222

Chae HM, Jeon BR, Lee SY, Ohga S (2017) Effects of weather factors on fuel moisture contents of forestland in Chuncheon, South Korea. J Fac Agric Kyushu Univ 62:23-29

Chang Y, Zhu Z, Bu R, Chen H, Feng Y, Li Y, Hu Y, Wang Z (2013) Predicting fire occurrence patterns with logistic regression in Heilongjiang Province, China. Landsc Ecol 28:1989-2004

Chen DK, Zhou XF, Zhao HX, Wang YH, Jing YY (1982) Study on the structure, function and succession of the four types in natural secondary forest. J Northeast For Univ 10(2):1-20
Chuvieco E, Aguado I, Dimitrakopoulos AP (2004) Conversion of fuel moisture content values to ignition potential for integrated fire danger assessment. Can J For Res 34:2284-2293

De Leeuw J (2009) Journal of statistical software. Wiley Interdiscip Rev Comput Stat 1:128-129

Finney MA, Cohen JD, Grenfell IC, Yedinak KM (2010) An examination of fire spread thresholds in discontinuous fuel beds A. Int J Wildl Fire 19:163-170

Flannigan MD, Wotton BM, Marshall GA, Groot De, de Groot WJ, Johnston J, Jurko N, Cantin AS (2016) Fuel moisture sensitivity to temperature and precipitation: climate change implications. Clim Change 134(1-2):59-71

Fosberg MA (1975) Heat and water vapor flux in conifer forest litter and duff: a theoretical model. Rocky Mountain Forest and Range Experiment Station, Forest Service, US Department of Agriculture, $\mathrm{p} 152$

Golub GH, Heath M, Wahba G (1979) Generalized cross-validation as a method for choosing a good ridge parameter. Technometrics 21:215-223

Hu HQ, Lu X, Sun L, Guan D (2016) Dynamics and prediction models of ground surface dead fuel moisture content for typical stands in Great Xing'an Mountains, Northeast China. J Appl Ecol 27:2212-2224

Krivtsov V, Gray A, Valor T, Legg CJ, Davies GM (2008) The fuel moisture content of peat in relation to meteorological factors. WIT Trans Ecol Environ 119:193-200

Larsen AK (2015) GAM: the predictive modeling silver bullet. Public 1986:1-27

Li J, Song Y, Huang X, Li M (2015) Comparison of forest burned areas in mainland China derived from MCD45A1 and data recorded in yearbooks from 2001 to 2011. Int J Wildl Fire 24:103-113

Liu Z, Yang J, He HS (2013) Identifying the threshold of dominant controls on fire spread in a boreal forest landscape of Northeast China. PLoS ONE 8(1):e55618

Lydersen JM, Collins BM, Coppoletta M, Jaffe MR, Northrop H, Stephens SL (2019) Fuel dynamics and reburn severity following high-severity fire in a Sierra Nevada, USA, mixed-conifer forest. Fire Ecol 15:43. https://doi.org/10.1186/s42408-019-0060-x

Matthews S (2006) A process-based model of fine fuel moisture. Int J Wildl Fire 15:155-168

Matthews S (2014) Dead fuel moisture research: 1991-2012. Int J Wildl Fire 23:78-92

Matthews S, Gould J, McCaw L (2010) Simple models for predicting dead fuel moisture in eucalyptus forests. Int $\mathrm{J}$ Wildl Fire 19:459-467

Nelson JRM (2001) Water relations of forest fuels. In: Forest fires. Academic Press, pp 79-149

Nelson RM Jr (1984) A method for describing equilibrium moisture content of forest fuels. Can J For Res 14:597-600

Nelson RM, Hiers JK (2008) The influence of fuelbed properties on moisture drying rates and timelags of longleaf pine litter. Can J For Res 38:2394-2404

Pippen BG (2008) Fuel moisture and fuel dynamics in woodland and heathland vegetation of the Sydney Basin. University of New South Wales, Australian Defence Force Academy, School of Physical, Environmental and Mathematical Sciences

Possell M, Bell TL (2013) The influence of fuel moisture content on the combustion of Eucalyptus foliage. Int J Wildl Fire 22:343-352

RStudio Team (2018) RStudio: Integrated Development for R. RStudio, PBC, Boston, MA. http://www.rstudio.com/

Schroeder M, Buck C (1970) Fire weather: a guide for application of meteorological information to forest fire control operations. USDA For Serv Washington, DC 360:236

Schunk C, Wastl C, Leuchner M, Menzel A (2017) Fine fuel moisture for site- and species-specific fire danger assessment in comparison to fire danger indices. Agric For Meteorol 234-235:31-47 
Sen J, Wan-long L (2014) Prediction on moisture contents of typical forest-land surface dead fuels in Nanchang city, Jinagxi province: method optimization and FWI applicability. J Cent South Univ For Technol. https://doi.org/10.14067/j.cnki.1673-923x.2014.11.001

Shen W, Li M, Huang C, Tao X, Li S, Wei A (2019) Mapping annual forest change due to afforestation in Guangdong Province of China using active and passive remote sensing data. Remote Sens 11(5):490

Simard AJ (1968) The moisture content of forest fuels - I: a review of basic concepts. Information report FF-X-14. Forest fire research institute, Department of Forestry and Rural Development. pp 47

Slijepcevic A, Anderson WR, Matthews S (2013) Testing existing models for predicting hourly variation in fine fuel moisture in eucalypt forests. For Ecol Manage 306:202-215

Slijepcevic A, Anderson WR, Matthews S, Anderson DH (2015) Evaluating models to predict daily fine fuel moisture content in eucalypt forest. For Ecol Manage 335:261-269

Sun P, Yu HZ, Jin S (2015) Predicting hourly litter moisture content of larch stands in Daxinganling Region, China using three vapourexchange methods. Int J Wildl Fire 24(1):114-119

Sun P, Zhang Y, Sun L, Hu H, Guo F, Wang G, Zhang H (2018) Influence of fuel moisture content, packing ratio and wind velocity on the ignition probability of fuel beds composed of Mongolian oak leaves via cigarette butts. Forests 9(9):507

Syphard AD, Rustigian-Romsos H, Mann M, Conlisk E, Moritz MA, Ackerly D (2019) The relative influence of climate and housing development on current and projected future fire patterns and structure loss across three California landscapes. Glob Environ Chang 56:41-55

Van Wagner CE, Pickett TL (1985) Equations and FORTRAN program for the Canadian forest fire weather index system. Can For Serv For Tech Rep 1985:33
Viney NR, Hatton TJ (1990) Modelling the effect of condensation on the moisture content of forest litter. Agric For Meteorol 51:51-62

Wang C (2006) Biomass allometric equations for 10 co-occurring tree species in Chinese temperate forests. For Ecol Manage 222:9-16

Weise DR, Fujioka FM, Nelson RM (2005) A comparison of three models of 1-h time lag fuel moisture in Hawaii. Agric For Meteorol 133:28-39

Wittich KP (2005) A single-layer litter-moisture model for estimating forest-fire danger. Meteorol Zeitschrift 14:157-164

Wood SN (2018) Book review: generalized additive models: an introduction with R (2nd Edition). https://doi.org/https://doi. org/10.18637/jss.v086.b01

Wood SN, Scheipl F, Faraway JJ (2013) Straightforward intermediate rank tensor product smoothing in mixed models. Stat Comput 23:341-360

Yu HZ, Shu LF, Deng JF, Yang G, Liang Q, Li JH, Zhu HY (2018) Prediction models and the extrapolation effects for water content of surface dead fuels in the typical stand of the great Xing' an mountains of china by one-hour time step. J Appl Ecol 29(12):3959-3968

Zhang H, Jin S, Di XY (2014) Seasonal dynamics and prediction of forest litter moisture in Daxing' anling region. For Res 27:683-688

Publisher's Note Springer Nature remains neutral with regard to jurisdictional claims in published maps and institutional affiliations. 